\title{
We all want to live longer, but not grow old
}

\author{
Simona Giampaoli', Giovanni Viscogliosi', Diego Vanuzzo² \\ 1 Department of Cardiovascular, Dysmetabolic and ageing diseases, Italian National Institute of Health, Rome \\ 2 National Association of Hospital Cardiologists (ANMCO), Florence, Italy
}

\begin{abstract}
Population ageing represents a "triumph" and a "challenge" for society.

The increase in life expectancy corresponds to an increase of risk factors and age-associated non communicable diseases, with consequent rise in health care costs and the burden of healthcare sustainability.

Aim of this analysis is to describe the prevalence of non communicable diseases, comorbidity and disability in non-institutionalized elderly population, aged 75-79 years, examined within the 0sservatorio Epidemiologico Cardiovascolare/Health Examination Survey.

Cardiovascular disease is the most frequent occurring in $27 \%$ of the examined population, followed by diabetes (24\%) and chronic kidney disease (21\%); $60 \%$ of examined elderly population suffers of one or more chronic diseases, while $40 \%$ is in a good health.

Ninety-three per cent of the examined population is free of disability; cognitive function disorders, assessed by the Folstein's Mini Mental State Examination, are recorded in 21\% men and 29\% women.

In the context of prevention, there is still much that needs to be done. It is important to initiate or maintain preventive actions concerning also this age-group at both community and individual level, to promote the cultural notion that a good quality of life in advanced age is built day by day starting from one's youth through a healthy diet, regular physical activity and non-smoking habit.
\end{abstract}

Corresponding author: Simona Giampaoli, Istituto Superiore di Sanità, Department Cardiovascular Dysmetabolic and ageing-associated diseases, Viale Regina Elena 299, 00161 Roma, Italy.

Tel. +39 0649904231 - Fax +390649904227.

E-mail: simona.giampaoli@iss.it

Key words: Osservatorio Epidemiologico Cardiovascolare/Health Examination Survey; healthy ageing; prevalence of non-communicable diseases; elderly people.

Received for publication: 24 January 2017

Accepted for publication: 31 January 2017

CC Copyright S. Giampaoli et al., 2017

Tipografia PI-ME Editrice, Italy

Monaldi Archives for Chest Disease 2017; 87:843

doi: 10.4081/monaldi.2017.843

This article is distributed under the terms of the Creative Commons Attribution Noncommercial License (by-nc 4.0) which permits any noncommercial use, distribution, and reproduction in any medium, provided the original author(s) and source are credited.

\section{Introduction}

Italy continues to be one of the countries with the highest proportion of people aged $\geq 65$ years in the world - today this age-group constitutes $20 \%$ of the population. The latest ISTAT (National Bureau of Statistics) projections indicate that in 2051 one-third of all Italians will be 65 years or older. According to data from the WHO Global Burden of Disease Study 2010 Country Profiles, life expectancy in Italy is 81.5 years and in the last 10 years, among countries with similar income level, Italy has passed from $4^{\text {th }}$ to $2^{\text {nd }}$ position after Japan, and is ranked $3^{\text {rd }}$ in terms of years lived in good health (70.2 years) [1]. Population ageing represents both a "triumph" and a "challenge" for society. The general increase in life expectancy corresponds to an increase in age-linked chronic degenerative diseases, with a consequent rise in healthcare costs and the burden of healthcare sustainability.

In the face of this scenario, the WHO has recently outlined a strategy of health promotion and support of the elderly person, designated with the name "Active Ageing", whose aim is to promote a new concept of ageing and enhance the quality of life of elderly people in society [2]. To support this strategy, it recommends the implementation of health population and health care surveillance. Hence, now more than ever before it is necessary that the planning and implementation of interventions be based on systematic, detailed quality information on the needs of the elderly population, and on the evolution of the health and social issues linked to ageing. This information is essential to assess the efficacy of the actions already undertaken, rationalize the available resources, and redress the widening gap of health and social inequalities within this age-group of the population. This information is available thanks to data collected through the Osservatorio Epidemiologico Cardiovascolare/Health Examination Survey carried out in the framework of the ANMCO-HCF-ISS joint agreement [3].

\section{Materials and Methods}

The Osservatorio Epidemiologico Cardiovascolare/Health Examination Survey was an cross-section epidemiological survey conducted between 2008 and 2012 on representative samples of the general population aged 35-79 years (the samples were extracted from the lists of residents of 23 municipalities which adhered to the survey, distributed throughout 20 regions of Italy), the samples consisting of 220 persons every 1.5 million inhabitants. All procedures and methodologies adopted in the screening process were in accordance with the recommendations and international quality controls, and have been amply described elsewhere [3,4]. In the age-group considered here (75-79 years), the subjects who participated represented only $50 \%$ of those enrolled; hence these data, although indicative, should be interpreted with caution and, given the age, they could represent that part of the non-institutionalized population with the best health status. 
The diagnostic criteria adopted relative to the diseases considered were, briefly, as follows: respiratory diseases included bronchial asthma and diagnosed chronic obstructive pulmonary disease (COPD); chronic kidney disease (CKD) was defined as glomerular filtration rate $<60 \mathrm{~mL} / \mathrm{min} / 1.73 \mathrm{~m}^{2}$ or urine albumin/creatinine ratio $\geq 30 \mathrm{mg} / \mathrm{g}$; diabetics were defined as having fasting glycemia $\geq 126 \mathrm{mg} / \mathrm{dl}$ or if under specific treatment; cardiovascular diseases (CVD) included the following conditions: myocardial infarction, stroke, angina pectoris, atrial fibrillation, left ventricular hypertrophy, transient ischemic attack, intermittent claudication as documented in the patient's medical record or defined by means of a specific standardized questionnaire and the ECG Minnesota code classification [5]; presence of cancer was based on patient self-report and review of the patient's medical record; chronic liver disease was also defined by patient self-report and review of the medical record.

Disability was analyzed in those who completed the Instrumental Activities of Daily Living (IADL) questionnaire, in particular the ability to: use the phone, take medications, manage one's finances, and do shopping; for the assessment of Basic Activities of Daily Living (BADL), the following items were added: eating without need for assistance, getting dressed and undressed without need for assistance, having a shower or bath without need for assistance [6].

Finally, the Mini Mental State Examination (MMSE) was considered for the assessment of cognitive deficit, adjusted for age and educational level; subjects who scored lower than 24/30 were considered as having a cognitive decline [7]. This parameter was analyzed on a smaller number of subjects in that the questionnaire was administered in only 14 out of 20 regions.

Table 1. Osservatorio Epidemiologico Cardiovascolare/Health Examination survey: prevalence of the major chronic diseases in the non-institutionalized population aged 75-79 years.

\begin{tabular}{lccc} 
Chronic diseases & \% & \multicolumn{2}{c}{$\mathbf{9 5 \%}$ CI } \\
\hline Chronic respiratory diseases & 15.4 & 12.8 & 18.0 \\
\hline Chronic kidney disease & 20.7 & 17.6 & 23.7 \\
\hline Diabetes & 23.6 & 20.6 & 26.6 \\
\hline Cardiovascular diseases & 27.0 & 23.9 & 30.1 \\
\hline Cancer & 9.8 & 7.6 & 11.9 \\
\hline Chronic liver diseases & 0.7 & 0.1 & 1.2 \\
\hline
\end{tabular}

\section{Results}

The data reported below refer to 799 non-institutionalized individuals (429 males and 370 females), aged between 75 and 79 years, distributed throughout 20 Italian regions. Table 1 reports the prevalence of the principal chronic diseases based on the diagnostic criteria adopted by the study and reported above in the Methods. As can be clearly seen, CVD, CKD and diabetes showed the highest prevalence. No chronic disease was present in 37.4\% [95\% confidence interval (CI): 33.6-41.1] of participants, while 19\% (CI 15.9-22.0) had 2 diseases, and 6.8\% (CI 4.88.7 ) had 3 or more diseases. Among those with at least two comorbidities, CVD and diabetes were the two most frequently combined (26.8\%), followed by CVD and respiratory diseases (13.4\%), CVD and cancer (12.2\%), CVD and CKD (11.6\%), and CKD and diabetes (10.4\%). Arterial hypertension was the most prevalent high-risk condition found in this age-group, being present in 78.3\% (74-82) of men and $81.3 \%$ (CI 77-83) of women. Of the men with hypertension, $25 \%$ were not aware they had this condition, while $18.7 \%$ of the women were not aware they had hypertension. Only $30 \%$ of the men with hypertension and $22.3 \%$ of the women with hypertension were receiving adequate healthcare, while $42 \%$ of men with hypertension and $54 \%$ of women with hypertension were not below the satisfactory level of $140 / 90 \mathrm{mmHg}$.

Table 2 reports data on disability for the principal items of IADL: $92.8 \%$ of participants had no physical disability. Doing the shopping was the item reported as posing most difficulty. Table 2 reports also disability in the BADL: $96.6 \%$ of participants reported not having any disability, while getting dressed and undressed alone (without the need for help) was reported as the most compromised activity.

The mean score on the MMSE, adjusted for age and education, was 25.7 for men and 25.0 for women; an age- and education-adjusted score $<24$ was found in $21.4 \%$ of men and $29 \%$ of women (Table 3 ).

Table 3. Osservatorio Epidemiologico Cardiovascolare/Health Examination survey: mean score on the Mini Mental State Examination (mean \pm standard deviation) and prevalence of cognitive decline in non-institutionalized males and females aged 75-79 years.

\begin{tabular}{lcc} 
& Males & Females \\
MMSE score & $25.7 \pm 3.6$ & $25.0 \pm 4.0$ \\
\hline MMSE $<24 / 30$ & $21.4 \%($ CI $16.5-26.6)$ & $29.0($ CI 23.1-35.2) \\
\hline
\end{tabular}

Table 2. Osservatorio Epidemiologico Cardiovascolare/Health Examination survey: prevalence of the main physical disabilities from the IADL and BADL in the non-institutionalized population aged 75-79 years.

\begin{tabular}{|c|c|c|c|c|c|c|}
\hline IADL & & Disability & CI & BADL & Disability & CI \\
\hline & & $\%$ & $95 \%$ & & $\%$ & $\mathbf{9 5} \%$ \\
\hline Use of telephone & & 2.5 & $1.1-4.0$ & Eating without aid & 1.1 & $0.2-2.2$ \\
\hline Taking medications & & 2.5 & $1.1-4.0$ & Getting dressed/undressed on one's own & 2.5 & $1.1-4.0$ \\
\hline Managing finances & & 3.8 & $2.0-5.6$ & Bathing or showering alone & 2.2 & $1.1-3.6$ \\
\hline Doing shopping & & 5.8 & $3.6-8.1$ & & & \\
\hline N. disabilities IADL & & & & N. disabilities BADL & & \\
\hline & 0 & 92.8 & $90.4-95.1$ & 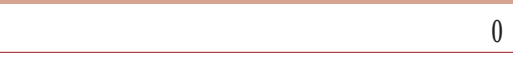 & 96.6 & $94.9-98.2$ \\
\hline & 1 & 3.6 & $2.0-5.4$ & 1 & 1.6 & $2.0-5.4$ \\
\hline & 2 & 1.3 & $0.4-2.5$ & 2 & 1.1 & $0.4-2.5$ \\
\hline & 3 & 0.7 & $0.0-1.6$ & 3 & 0.7 & $0.0-1.6$ \\
\hline & 4 & 1.6 & $0.5-2.7$ & & & \\
\hline
\end{tabular}




\section{Discussion}

When speaking about life expectancy, it is necessary to estimate the life expectancy also in terms of years lived in good health. Notwithstanding an overall improvement in health status, and the progress in awareness about risk factors and the possibility of preventing disease, people today live in good health until 70 years of age, but the following 10 years are lived in non optimal conditions due to the presence of a cardiovascular disease, often associated with other chronic-degenerative diseases (diabetes, respiratory disease, cancer, CKD, or liver disease); CVD can be prevented also in advanced age thanks to the availability of highly effective therapies and the greater awareness of the beneficial effects of a healthy life style at whatever age [8]. For this reason, it is necessary to start preventive actions at both individual and population level to improve the conditions of life in advanced age.

The data from the Osservatorio Epidemiologico Cardiovascolare/ Health Examination Survey on the 75-79 year age-group across all regions of Italy show that almost $60 \%$ of elderly persons in this age-group suffer from a chronic-degenerative disease, but the remaining $40 \%$ enjoy good health status; $80 \%$ are affected by a condition such as arterial hypertension, which constitutes one of the principal factors for the development of CVD and age-related diseases, but the data we gathered show that only $30 \%$ of the men and $22 \%$ of the women are on adequate treatment. Disability in this age-group is still limited to a small number of people, inferior to $6-7 \%$ of the sample surveyed. More preoccupying are the cognitive decline, in that more than $20 \%$ of men and $29 \%$ of women are affected by a cognitive decline. We should not forget, however, that the rate of participation in this age-group was 50\%, and normally the people who present for an active screening are the ones who know they have a better health status. In the context of prevention, there is still much that needs to be done. It is important to initiate or maintain pre- ventive actions concerning also this age-group at both community and individual level. It is fundamental to promote the cultural notion that a good quality of life in advanced age is built day by day starting from one's youth through a healthy diet (varied, well-balanced and of modest portions), regular daily physical activity, and nonsmoking.

\section{References}

1. WHO. Global Burden of Disease 2010, Country profile, Italy.

2. WHO. Global Action Plan for the Prevention and Control of Noncommunicable Diseases (NCD), 2013-2020.

3. Giampaoli S, Vanuzzo D, Gruppo di Ricerca del Progetto Osservatorio Epidemiologico Cardiovascolare/Health Examination Survey. La salute cardiovascolare degli italiani. Terzo Atlante Italiano delle Malattie Cardiovascolari. Edizione 2014. G Ital Cardiol, vol 15 suppl 1, N. 4, 1S-31S.

4. Giampaoli S, Palmieri L, Donfrancesco C, et al. Cardiovascular health in Italy. Ten-year surveillance of cardiovascular diseases and risk factors: Osservatorio Epidemiologico Cardiovascolare/Health Examination Survey 1998-2012. Eur J Prev Cardiol 2015;22(2 Suppl): 9-37.

5. Luepker RV, Evans A, McKeigue P, Reddy KS. Cardiovascular Survey Methods. 2004. WHO Geneva.

6. Heikkinen E, Waters WE, Brzezinski ZJ. The elderly in eleven countries. A sociomedical survey. Public Health in Europe 21, WHO, Copenhagen, 1983.

7. Folstein MF, Folstein SE, McHugh PR. Mini-Mental State. A practical method for grading the cognitive state for the clinician. J Physchiat Res 1975;12:189-98.

8. Liu K, Daviglus M, Loria C, et al. Healthy lifestyle through young adulthood and the presence of low cardiovascular disease risk profile in middle age. Circulation 2012;125:996-1004. 